Marine Pollution Bulletin, vol. 151, 2020, pp. 11087-7.

\title{
Abundance and distribution of microplastics on sandy beaches of Lima, Peru.
}

De-la-Torre, Gabriel Enrique, Dioses-Salinas, Diana Carolina, Castro, Jasmin Marlith, Antay, Rosabel, Fernández, Naomy Yupanqui, Espinoza-Morriberón, Dante y Saldaña-Serrano, Miguel.

Cita:

De-la-Torre, Gabriel Enrique, Dioses-Salinas, Diana Carolina, Castro, Jasmin Marlith, Antay, Rosabel, Fernández, Naomy Yupanqui, EspinozaMorriberón, Dante y Saldaña-Serrano, Miguel (2020). Abundance and distribution of microplastics on sandy beaches of Lima, Peru. Marine Pollution Bulletin, 151, 11087-7.

Dirección estable: https://www.aacademica.org/gabriel.e.delatorre/3 ARK: https://n2t.net/ark:/13683/podQ/ceX

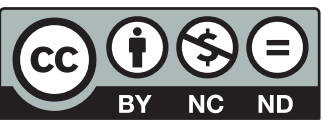


Baseline

\title{
Abundance and distribution of microplastics on sandy beaches of Lima, Peru $^{\text {th }}$
}

\author{
Gabriel Enrique De-la-Torre ${ }^{\mathrm{a}, *}$, Diana Carolina Dioses-Salinas ${ }^{\mathrm{a}}$, Jasmin Marlith Castro ${ }^{\mathrm{a}}$, \\ Rosabel Antay ${ }^{\mathrm{a}}$, Naomy Yupanqui Fernández ${ }^{\mathrm{a}}$, Dante Espinoza-Morriberón ${ }^{\mathrm{b}}$, \\ Miguel Saldaña-Serrano ${ }^{\mathrm{a}, \mathrm{c}}$ \\ ${ }^{a}$ Universidad San Ignacio de Loyola, Lima, Peru \\ ${ }^{\mathrm{b}}$ Instituto del Mar del Perú (IMARPE), Laboratorio de Modelado Oceanográfico, Ecosistémico y de Cambio Climático (LMOECC), Esquina General Gamarra y Valle, \\ Callao, Peru \\ ${ }^{\mathrm{c}}$ Laboratory of Biomarkers of Aquatic Contamination and Immunochemistry, Department of Biochemistry, Federal University of Santa Catarina, UFSC, Florianópolis, SC, \\ Brazil
}

\section{A R T I C L E I N F O}

\section{Keywords:}

Microplastic

Pollution

Sandy beach

FTIR

Polystyrene

Peru

\begin{abstract}
A B S T R A C T
Microplastic pollution is a problem of global scale, posing a threat to marine biota. To determine the current state of microplastic pollution on four popular sandy beaches of the coast of Lima, Peru, a sampling campaign was carried out in both intertidal and supralittoral zones. Microplastic abundance, type, size, color and distribution were recorded. The overall microplastic abundance was of the same order of magnitude as previous data obtained in Peru. Foams were the most abundant (78.3\%) microplastic type. Statistical analyses revealed significant differences between sites and zones. High variability of microplastic abundance was found among adjacent beaches and zones. Fourier Transform Infrared Spectroscopy (FTIR) analysis revealed that all foams were identified as polystyrene. The present results revealed an alarming level of microplastics present on Peruvian sandy beaches, but information about the sources, local dynamics and impacts of microplastics in this region are scarce, and thus further research is needed.
\end{abstract}

Annual production of plastic products around the world reached > 355 million tons in 2016 (PlasticsEurope, 2018). The impact of plastics in the marine environment is well documented, causing entanglement of marine species, ingestion and translocation of nonnative organisms (Derraik, 2002). Plastics reach the marine environment through land- or sea-based sources (Andrady, 2011), and have become a persistent and ubiquitous pollutant in the ocean (Hitchcock and Mitrovic, 2019). Microplastics are plastic particles smaller than $5 \mathrm{~mm}$ in diameter (Andrady, 2017; Crawford and Quinn, 2017), and can be classified in two categories: primary and secondary microplastics. Manufactured plastic particles of microscopic size are considered primary microplastics (Cole et al., 2011), while secondary microplastics are fragmented particles derived from larger plastics (Shim et al., 2018) due to its exposure to mechanical fragmentation and photolytic and biological degradation (Browne et al., 2007). Ingestion of microplastics have been reported in fish (Baalkhuyur et al., 2018;
Chagnon et al., 2018), marine mammals (Hernandez-Gonzalez et al., 2018), bivalves (Naidu, 2019), seabirds (Provencher et al., 2018; Thiel et al., 2018), and many other marine species (Rebolledo et al., 2013; Zhu et al., 2019). The potential risk of adsorbing contaminants from the environment and transferring through the food chain make microplastics a threat for marine species, ecosystems (Guzzetti et al., 2018), food security and, ultimately, human health (Barboza et al., 2018; Dela-Torre, 2019).

Coastal environments have been subject to microplastic pollution, including sandy beaches around the world (e.g. Hidalgo-Ruz and Thiel, 2013; Tiwari et al., 2019). In Peru, very few studies have addressed this issue (Ory et al., 2018; Purca and Henostroza, 2017). For that matter, the overall aims of this study were to: (1) evaluate the current state of microplastic pollution in four popular sandy beaches from the coast of Lima, and to (2) determine the characteristics and distribution of microplastics along the coast.

\footnotetext{
This research did not receive any specific grant from funding agencies in the public, commercial, or not-for-profit sectors.

* Corresponding author.

E-mail addresses: gabriel.delatorre@usil.pe (G.E. De-la-Torre), diana.dioses@usil.pe (D.C. Dioses-Salinas), Jasmin.castro@usil.pe (J.M. Castro), Rosabel.antay@usil.pe (R. Antay), Naomy.yupanqui@usil.pe (N.Y. Fernández), despinoza@imarpe.gob.pe (D. Espinoza-Morriberón), miguel.saldana@posgrad.ufsc.br (M. Saldaña-Serrano).
} 


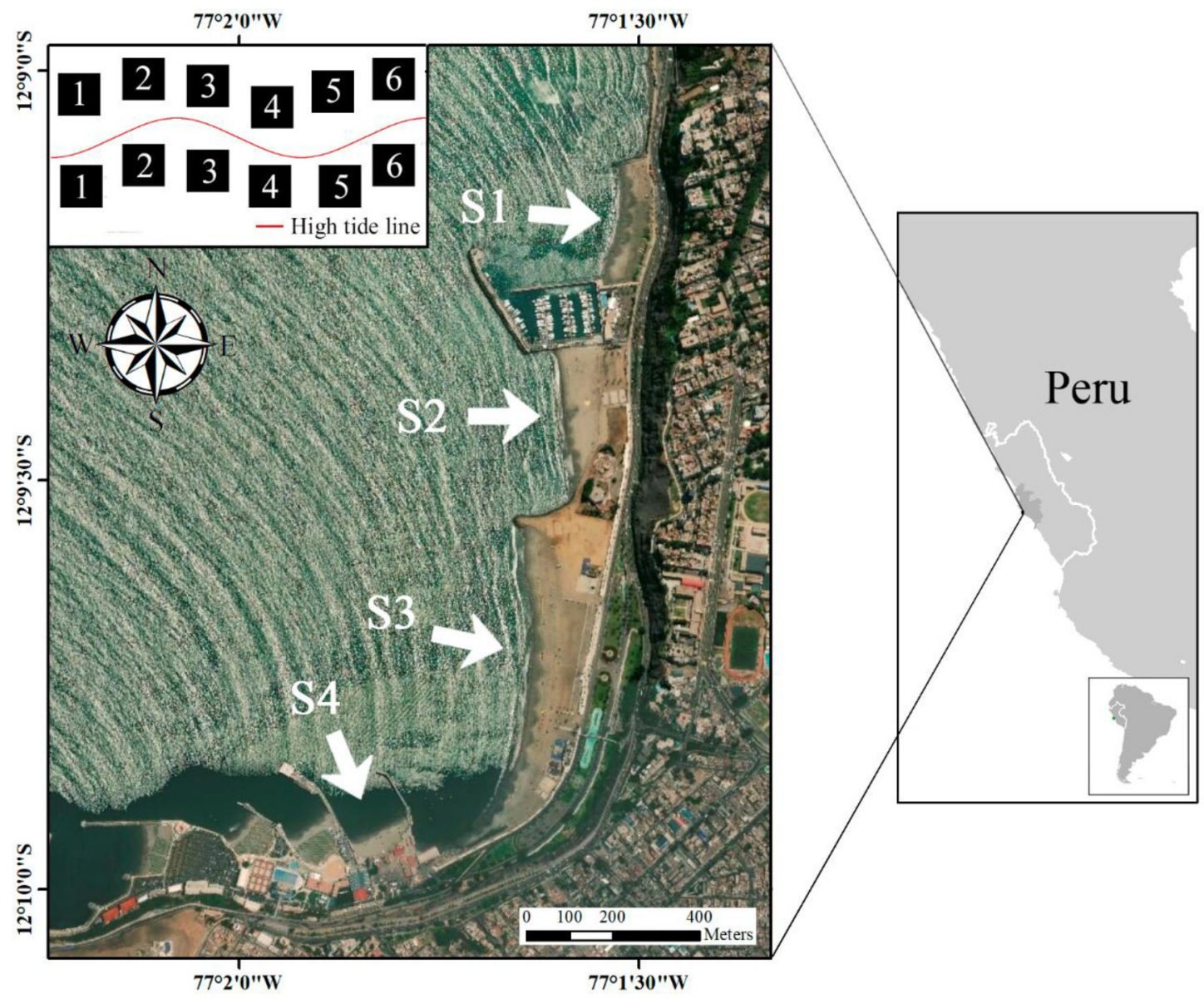

Fig. 1. Map showing the region and the sites selected in the coast of Lima. S1: Yuyos, S2: Sombrillas, S3: Agua Dulce, and S4: Pescadores. Black squares above the high tide line indicate the orientation of the transects from the supralittoral zone and below the transect from the intertidal zone.

A sampling campaign was carried out during March and April of 2018 (dry season), during low tide. Samples were collected from four adjacent sandy beach sites within the city of Lima (Fig. 1): Yuyos (12 $\left.09^{\prime} 11.1^{\prime \prime} \mathrm{S} 77^{\circ} 01^{\prime} 30.4^{\prime \prime} \mathrm{W}\right)$, Sombrillas $\left(12^{\circ} 09^{\prime} 24.9^{\prime \prime} \mathrm{S} 77^{\circ} 01^{\prime} 34.3^{\prime \prime} \mathrm{W}\right)$, Agua Dulce $\left(12^{\circ} 09^{\prime} 47.0^{\prime \prime} \mathrm{S} 77^{\circ} 01^{\prime} 36.7^{\prime \prime} \mathrm{W}\right)$ and Pescadores $\left(12^{\circ} 09^{\prime} 56.6^{\prime \prime} \mathrm{S}\right.$ $\left.77^{\circ} 01^{\prime} 49.2^{\prime \prime} \mathrm{W}\right)$. These beaches are very close to each other, each within a few hundred of meters. Yuyos, Sombrillas and Agua Dulce are very popular for beachgoers and small food businesses. At Pescadores beach, fishing boats are common and artisanal fishing activity is carried out daily. Due to its proximity, Agua Dulce is also influenced by fishing activity.

Sampling was performed following McDermid and McMullen (2004) with minor modifications. Every beach was divided into 12 transects, six belonging to the intertidal zone (ITZ) and the other six to the supralittoral zone (SLZ). The distance between transects varied depending on the beach length in order to cover most the ITZ and SLZ area in every beach. The ITZ was defined as the area between the high tide line and the low tide line, while the SLZ as the area above the high tide line (Fig. 1). To avoid bias by the strandline, sand samples were collected by randomly placing one $50 \times 50 \mathrm{~cm}^{2}$ quadrant in each transect ( $n=6$ per zone) and scooping the surface sand ( $1 \mathrm{~cm}$ deep) with a small metal shovel. Samples were taken to the laboratory for further analysis.

Wet samples were dried over night at room temperature. Once dried, sand samples were then sieved through a set of $1,2.8$ and $4.75 \mathrm{~mm}$ nested sieves. Residuals in each tray were placed separately in labeled glass petri dishes. Mesoplastics ( $\geq 5 \mathrm{~mm}$ particles) were discarded. Density separation was carried out by placing the residuals of every tray in $1 \mathrm{~L}$ glass beakers containing a saline solution $\left(120 \mathrm{~g} \mathrm{~L}^{-1}\right.$
$\mathrm{NaCl}$ ) and stirred for $15 \mathrm{~min}$ with a glass rod (Laglbauer et al., 2014). Floating microplastics were separated manually and placed in labeled glass petri dishes. When necessary, the morphology of some particles was observed under a stereomicroscope to further proof they were plastics. Microplastic abundance, size, type and color (white, blue, red, green, yellow, black, transparent and other colors) were recorded. Microplastic types followed their description by Wu et al. (2017): foam, fragment, pellet, sheet, film and fiber/line. To avoid confusion, the fiber/line type is defined as degraded textiles or finishing lines in the present study. No rigorous contamination control measures were needed, as this study aimed to assess microplastics from 1 to $4.75 \mathrm{~mm}$ in diameter. All microplastics were photographed.

A sample of 25 microplastics were selected ( 5 foams, 8 fragments, 7 pellets, and 5 fiber/lines) to be analyzed by Fourier transform infrared spectroscopy (FTIR) using a Perkin Elmer Frontier ${ }^{\mathrm{TM}}$ FT-IR at wavelengths between 500 and $4000 \mathrm{~cm}^{-1}$ and 30 scans. The obtained spectra were automatically compared with the reference spectra from the FTIR library and the polymer with the highest percentage of similarity was selected and accepted with a match $>80 \%$.

Microplastic abundance was expressed in particles $\mathrm{m}^{-2}$. ShapiroWilk tests invalidated the normal distributions of the data. To explain the distribution variability of microplastics among zones and beaches, a Generalized Linear Model (GLM) was developed. The predicted variable was the microplastic concentration $(M P C)$ and the predictive variables were the beach zone $(Z)$, the beach $(B)$ and the interaction between beach and zone $(Z \times B)$. While $M P C$ is a numeric variable, $B$ and $Z$ are factors. In order to normalize the distribution of the data, it was transformed by taking the base 10 logarithm of the values (LogMPC). Shapiro-Wilk test $(p>0.05)$ confirmed that the transformed variable 
Table 1

Number of microplastic particles of every type at each beach site.

\begin{tabular}{lrrrrr}
\hline Beach & Foams & Fragments & Pellets & Fibers/lines & Total \\
\hline S1 & 20 & 21 & 5 & 4 & 50 \\
S2 & 1230 & 195 & 43 & 1 & 1469 \\
S3 & 244 & 134 & 11 & 16 & 405 \\
S4 & 142 & 13 & 0 & 10 & 165 \\
Total & 1636 & 363 & 59 & 31 & 2089 \\
\hline
\end{tabular}

satisfied the assumption of normality. The model was formulated as follows:

$\log M P C \sim Z+B+Z \times B$

The residuals of the resulting model satisfied the assumption of normality (Shapiro-Wilk test, $p>0.05$ ). The parsimony of the models was evaluated using the Akaike Information Criterion (AIC). Significant level was set to 0.05 for all the analyses. All statistical analyses and models were conducted using R Software.

Results indicated that all the sampled beaches contained microplastics ranging from 1 to $4.75 \mathrm{~mm}$ in size. A total of 2089 microplastic particles were extracted and identified (Table 1). The highest abundance of microplastics was in S2 (489.7 \pm 143.5 particles $\left.\mathrm{m}^{-2}\right)$, followed by S3 $\left(135.0 \pm 25.97\right.$ particles $\left.\mathrm{m}^{-2}\right)$, S4 $(55.0 \pm 14.83$ particles $\left.\mathrm{m}^{-2}\right)$ and the lowest in $\mathrm{S} 1\left(16.67 \pm 4.26\right.$ particles $\left.\mathrm{m}^{-2}\right)$. Regarding microplastic types, $78.3 \%$ of the total microplastics were identified as foams and $17.38 \%$ were fragments, indicating that secondary microplastic dominated (Table 1). No sheets or films were found at any of the sampling sites. Most particles (54.2\%) were from 1 to $2.8 \mathrm{~mm}$ in size, the remaining $45.8 \%$ ranging from 2.9 to $4.75 \mathrm{~mm}$. Regarding color, the majority ( $84.8 \%)$ of the microplastics were white, followed by blue $(4.0 \%)$, red $(2.6 \%)$, green $(2.2 \%)$, yellow $(2.0 \%)$, and other colors (3.2\%).

Regarding the GLM results, the three predictive variables were statistically significant $(p<0.01)$, although showed different levels of contribution to the model (Table 2). The variable with the lowest percentage of contribution to explain the total variance of MPC was $Z$ $(2.68 \%)$, followed by $B(32.26 \%)$ and the interaction of the two variables $Z \times B(58.7 \%)$. MPC differences between the ITZ and SLZ did not show a great significance in the four sites (See Fig. 2). However, beach and both beach and zone together were the most relevant factors to the GLM. In addition, Tukey's HSD (honestly significant difference) posthoc test revealed five groups with no significant MPC difference ( $p>0.05)$ between them. These groups were S1-SLZ and S2-SLZ, S3SLZ and S4-SLZ, S1-ITZ and S2-ITZ, S4-SLZ and S3-ITZ, and S2-SLZ and S4-ITZ.

The number of analyzed particles by FTIR was not suitable for statistical analysis. The 25 selected particles were confirmed synthetic polymers according to their similarities with reference spectra from the FTIR library. Identified microplastics were high-density polyethylene HDPE (5 fragments and 7 pellets), isotactic polypropylene IPP (3 fragments), polystyrene PS (5 foams), polypropylene PP (4 fiber/lines) (Fig. 3). One fiber was identified as polyester, but the similarity percentage with the reference spectrum did not reach the $>80 \%$

Table 2

Analysis of the variance and AIC for the GLM.

\begin{tabular}{lcrrlrl}
\hline Model & $\begin{array}{l}\text { Residual } \\
\text { variance }\end{array}$ & Deviance & D.f. & $\begin{array}{l}\% \text { of total } \\
\text { variance } \\
\text { explained }\end{array}$ & AIC & p value \\
\hline Null & 22.656 & & & & 101.96 & \\
+ Zone & 22.049 & 0.607 & 1 & 2.68 & 102.71 & $<0.01$ \\
+ Beach & 22.049 & 7.309 & 3 & 32.26 & 90.19 & $<0.01$ \\
+ Zone $\times$ & 1.440 & 13.300 & 3 & 58.70 & -10.79 & $<0.01$ \\
Beach & & & & & & \\
\hline
\end{tabular}

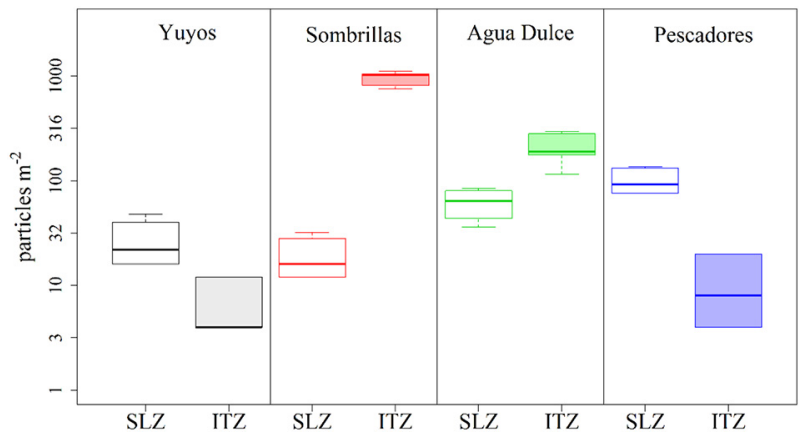

Fig. 2. Boxplot of the microplastic abundance (particles $\mathrm{m}^{-2}$ ) per beach and beach zone. SLZ: supralitoral zone, and ITZ: intertidal zone.

threshold.

The microplastic abundance of the present study is comparable to other regions. Results from a broader range along the Peruvian coast showed similarities in terms of variability (Purca and Henostroza, 2017), as their mean microplastic abundance were 40 particles $\mathrm{m}^{-2}$, 4.7 particles $\mathrm{m}^{-2}, 463.3$ particles $\mathrm{m}^{-2}$, and 11.3 particles $\mathrm{m}^{-2}$ for sites $1,2,3$ and 4 respectively. However, the average abundance for the Chilean continental coast is $27 \pm 2.6$ particles $\mathrm{m}^{-2}$, indicating minor levels of microplastic pollution in the SE Pacific, although microplastic abundance in the Eastern Island reached 805 particles $\mathrm{m}^{-2}$ due to the transportation of plastic debris by the Subtropical Gyre (Hidalgo-Ruz and Thiel, 2013). Microplastic abundance from other parts of the world are well documented and vary considerably depending on the specific region (Table 3 ). The use of different units made the comparison among areas of the world difficult (Barboza et al., 2019), so there is a need to harmonize methodologies for reporting the presence of microplastics in sandy beaches.

Foams were the most common microplastic type (78.32\%), followed by fragments (17.38\%). A high abundance of foams was also previously reported from sandy beaches from South Korea (Eo et al., 2018) and Russia (Esiukova, 2017). However, most of the studies from around the globe reported mainly fragments and fibers (Claessens et al., 2011; Hengstmann et al., 2018; Hidalgo-Ruz and Thiel, 2013; Lots et al., 2017; Qiu et al., 2015; Yu et al., 2016). Specific microplastic type occurrence depends on region-specific land-based activities and social behavior. S1, S2 are popular recreational beaches, while S4 has a constant fishing activity and S3 has partially both. It is important to note that Lima is the most populated city in Peru and, more specifically, in S2 and S3 local food businesses provide many single-use of styrofoam materials, like plates, cups and boxes. Besides, the presence of weathered buoys in the ocean may detach small foam debris to the ocean. Thus, here the sources of small expanded polystyrene are different than in South Korea, Russia or southern Chile where these derive from aquaculture floats (Eo et al., 2018; Esiukova, 2017; Hinojosa and Thiel, 2009).

The majority of the microplastics were white in color, and $92.32 \%$ of the white colored particles were foams. Thus, the high abundance of foams has a considerable influence over the overall color proportion. Color influences microplastic ingestion by selective marine species (Ory et al., 2017), reason why it is an important factor. The predominant colors reported on beaches and in coastal waters from Sri Lanka were blue (29\%) and green (23\%) (Koongolla et al., 2018).

A study on the surface sediment of the Bering Sea-Chukchi Sea shelf showed that the most common microplastics ranged from 0.10 to $2.0 \mathrm{~mm}$ (Mu et al., 2019); data obtained on a research conducted in Japan, Thailand, Malaysia and South Africa using box corers showed that the size of most microplastics from the sediments ranged from $315 \mu \mathrm{m}$ to $1 \mathrm{~mm}$ (Matsuguma et al., 2017). The microplastics of the two size ranges (from 1 to $2.8 \mathrm{~mm}$ and from 2.8 to $4.75 \mathrm{~mm}$ ) obtained in the present study are very similar in proportion, although particles smaller 

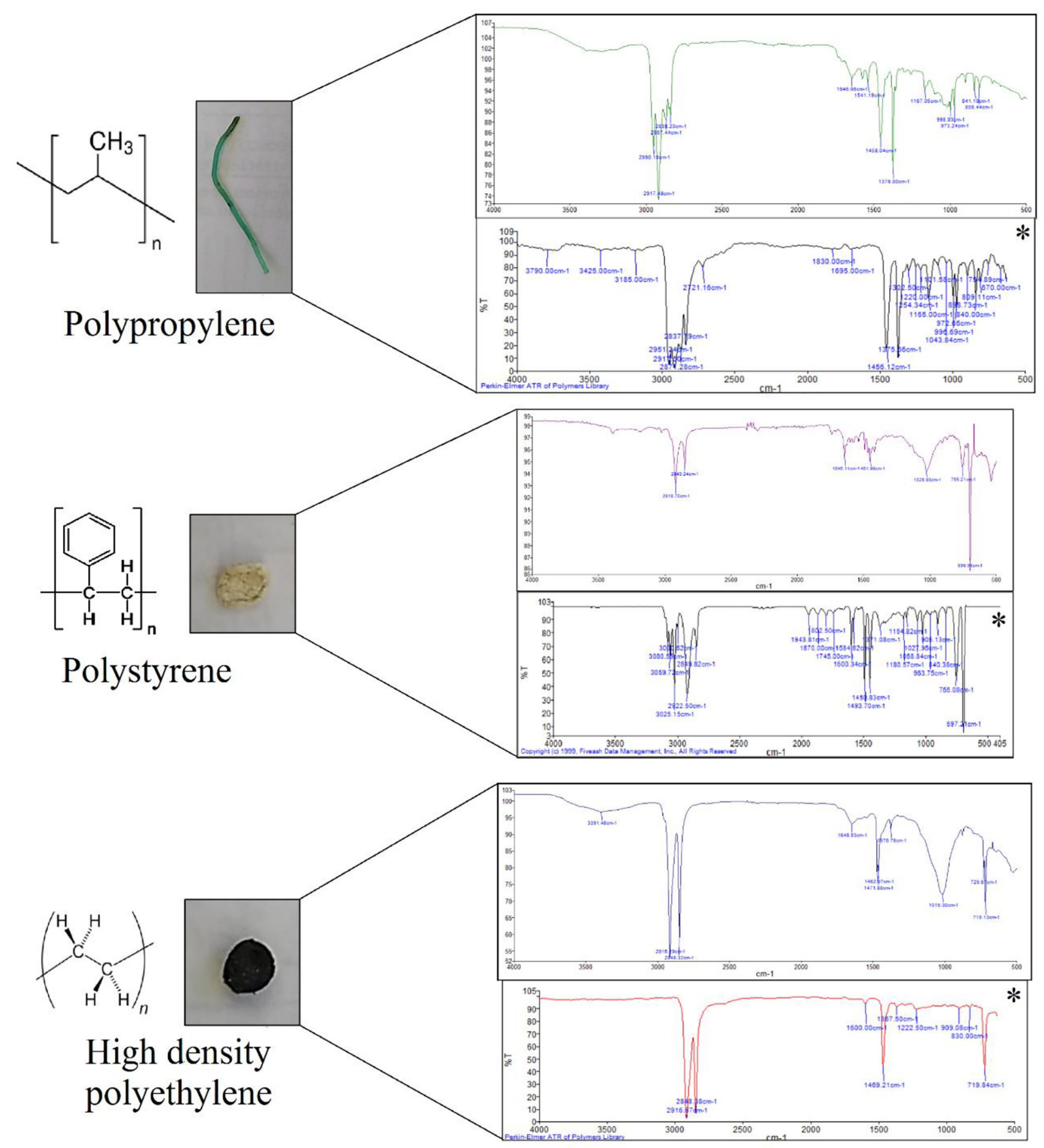

Fig. 3. Examples of different microplastic types with their FTIR spectrum. *: reference spectrum.

than $1 \mathrm{~mm}$ were not extracted.

Washed up microplastics are mainly due to landward winds and currents (Isobe et al., 2014). In this case specifically, the Peru Coastal Current (PCC) is a surface wind-driven current flowing northward along the Peruvian coast (Chaigneau et al., 2013). Thus, surface currentdriven microplastic washing ashore is very likely in this region, however more studies in Peruvian coast are needed to fully understand this process. The present results showed that S2 (489.7 \pm 143.5 particles $\left.\mathrm{m}^{-2}\right)$ and S3 (135.0 \pm 25.97$)$ were the beaches most contaminated by microplastics and with also a higher microplastic abundance in the ITZ. S1 and S4 have man-made structures interfering with the natural surface current flow (Fig. 1), suggesting that microplastics that are being driven by the currents may not be impacting directly on them. This may also explain low microplastic occurrence in the ITZ of these beaches. Aguilera et al. (2016) showed that artificial intertidal breakwaters promote retention and accumulation of human-derived litter and entrapment of floating debris. The presence of these artificial structures strongly influences over tidal activity in S1 and S4 and may serve as a barrier and trap for floating microplastics, resulting in the low abundance of stranded microplastics in the ITZ. It should be noted that although S4 is a small beach surrounded by manmade structures, it has a high daily fishing activity. Since ocean currents are a key factor to 
Table 3

Microplastic abundance on sandy beaches from different regions and the present study *: Median.

\begin{tabular}{|c|c|c|}
\hline Region & $\begin{array}{l}\text { Mean abundance (particles } \\
\mathrm{m}^{-2} \text { ) }\end{array}$ & Reference \\
\hline South Korea & 8205 & Lee et al., 2015 \\
\hline South Korea & $976 \pm 405$ & Heo et al., 2013 \\
\hline Chile (Easter Island) & $805 \pm 320.1$ & $\begin{array}{l}\text { Hidalgo-Ruz and Thiel } \\
2013\end{array}$ \\
\hline USA & $413.8 \pm 76.7$ & Gray et al., 2018 \\
\hline Peru & $174.1 \pm 44.8\left(42^{*}\right)$ & This study \\
\hline India & 68.8 & Jayasiri et al., 2013 \\
\hline USA & $50.6 \pm 9.96$ & Wessel et al., 2016 \\
\hline India & $46.6 \pm 37.2$ & Karthik et al., 2018 \\
\hline Chile (Continental) & $27 \pm 2.6$ & $\begin{array}{l}\text { Hidalgo-Ruz and Thiel, } \\
2013\end{array}$ \\
\hline
\end{tabular}

determine the distribution and movements of microplastics along coastal regions, it is necessary to study this natural phenomenon and focus on micro-debris translocation in this region. Another important factor to consider is the continuous disposal of styrofoam materials to the beach by beachgoers. The lack of weathering indicators in sampled white foams (PS), like brown or greenish coloring of the originally white particles, suggests that many of these particles had been recently emitted by the source (the breakdown of styrofoam debris) on site.

Extra peaks in the IR spectrum of the analyzed microplastics in contrast with the library pattern may be due to plastic polymer degradation and adsorption of other contaminants during their voyage in the ocean. The absence of polyvinyl chloride (PVC) and polyethylene terephthalate (PET) may be attributed to their high densities (1.16-1.58 $\mathrm{g} \mathrm{cm}^{-3}$ and 1.37-1.45 $\mathrm{g} \mathrm{cm}^{-3}$ ) (Karthik et al., 2018). High density plastics tend to settle on the seafloor, although their sinking rates are influenced by other factors, like sea surface tension, size or shape (Shim et al., 2018). All the analyzed foams were identified as PS. High abundance of PS debris could be subject to leaching of styrene oligomers (SOs) and posing a long-term risk to the marine environment (Kwon et al., 2015). SOs are ubiquitous in surface and deep seawater (Kwon et al., 2017), and thus a SOs monitoring system in beach sand and water column is necessary to assess the impact in marine organisms in the area.

The present study described the distribution and characteristics of microplastics on four sandy beaches of Lima, Peru. A high variation of microplastic abundance was found between beaches. S2 had the highest microplastic abundance $\left(489.7 \pm 143.5\right.$ particles $\left.\mathrm{m}^{-2}\right)$. Polystyrene (78.31\%), which also resulted in the dominance of white plastics, and fragments $(17.38 \%)$ were the most abundant microplastic type. Little difference was found between the amounts of microplastics of different sizes. The overall microplastic abundance of every beach may be attributed to the PCC, man-made structures interfering with the microplastic-driver currents and contamination with single-use styrofoam materials provided by local food business located within the beach area in S2 and S3. A significant difference was found between tidal zones on all beaches. The chemical composition of all the foam samples was PS, thus indicating that this was the most important microplastic in the region and a potential threat of styrene oligomer pollution in the area. Furthermore, as this present study and other studies from the region have focused mostly on the larger fraction of microplastics $(1-5 \mathrm{~mm})$, more research is needed specially focused on microplastics of smaller sizes $(0.01-1 \mathrm{~mm})$.

\section{CRediT authorship contribution statement}

Gabriel Enrique De-la-Torre: Conceptualization, Methodology, Formal analysis, Writing - original draft, Project administration. Diana Carolina Dioses-Salinas: Investigation, Resources, Data curation. Jasmin Marlith Castro: Investigation, Resources. Rosabel Antay:
Investigation, Resources. Naomy Yupanqui Fernández: Investigation, Resources. Dante Espinoza-Morriberón: Formal analysis, Validation, Writing - review \& editing. Miguel Saldaña-Serrano: Conceptualization, Validation, Formal analysis, Resources, Writing review \& editing, Supervision.

\section{Declaration of competing interest}

The authors declare that they have no known competing financial interests or personal relationships that could have appeared to influence the work reported in this paper.

\section{Acknowledgements}

The authors are thankful to M.Sc. Luis Santillan for his comments and observations during the drafting of the present study, to M.Sc. July Zegarra for her continuous support, and to all the volunteers from the Red Universitaria Ambiental (RUA - Nodo USIL) for their unconditional assistance during the sampling campaigns.

\section{References}

Aguilera, M.A., Broitman, B.R., Thiel, M., 2016. Artificial breakwaters as garbage bins: structural complexity enhances anthropogenic litter accumulation in marine intertidal habitats. Environ. Pollut. 214, 737-747. https://doi.org/10.1016/j.envpol. 2016.04.058.

Andrady, A.L., 2011. Microplastics in the marine environment. Mar. Pollut. Bull. 62, 1596-1605. https://doi.org/10.1016/j.marpolbul.2011.05.030.

Andrady, A.L., 2017. The plastic in microplastics: a review. Mar. Pollut. Bull. 119, 12-22. https://doi.org/10.1016/j.marpolbul.2017.01.082.

Baalkhuyur, F.M., Bin Dohaish, E.A., Elhalwagy, M.E.A., Alikunhi, N.M., AlSuwailem, A.M., Røstad, A., Coker, D.J., Berumen, M.L., Duarte, C.M., 2018. Microplastic in the gastrointestinal tract of fishes along the Saudi Arabian Red Sea coast. Mar. Pollut. Bull. 131, 407-415. https://doi.org/10.1016/j.marpolbul.2018.04.040.

Barboza, L.G.A., Vethaak, A.D., Lavorante, B.R.B.O., Lundebye, A.K., Guilhermino, L., 2018. Marine microplastic debris: an emerging issue for food security, food safety and human health. Mar. Pollut. Bull. 133, 336-348. https://doi.org/10.1016/j. marpolbul.2018.05.047.

Barboza, L.G.A., Frias, J.P.G.L., Booth, A.M., Vieira, L.R., Masura, J., Baker, J., Foster, G., Guilhermino, L., 2019. Chapter 18 - microplastics pollution in the marine environment. In: Sheppard, C. (Ed.), World Seas: An Environmental Evaluation - Volume III: Ecological Issues and Environmental Impacts, 2nd edn. Elsevier, Amsterdam, pp. 329-351.

Browne, M.A., Galloway, T., Thompson, R., 2007. Microplastic-an emerging contaminant of potential concern? Integr. Environ. Assess. Manag. 3, 559-561. https:// doi.org/10.1002/ieam.5630030412.

Chagnon, C., Thiel, M., Antunes, J., Ferreira, J.L., Sobral, P., Ory, N.C., 2018. Plastic ingestion and trophic transfer between Easter Island flying fish (Cheilopogon rapanouiensis) and yellowfin tuna (Thunnus albacares) from Rapa Nui (Easter Island). Environ. Pollut. 243, 127-133. https://doi.org/10.1016/j.envpol.2018.08.042.

Chaigneau, A., Dominguez, N., Eldin, G., Vasquez, L., Flores, R., Grados, C., Echevin, V., 2013. Near-coastal circulation in the Northern Humboldt Current System from shipboard ADCP data. J Geophys Res Oceans 118, 5251-5266. https://doi.org/10. 1002/jgrc.20328, 2013.

Claessens, M., Meester, S.D., Landuyt, L.V., Clerck, K.D., Janssen, C.R., 2011. Occurrence and distribution of microplastics in marine sediments along the Belgian coast. Mar. Pollut. Bull. 62, 2199-2204. https://doi.org/10.1016/j.marpolbul.2011.06.030.

Cole, M., Lindeque, P., Halsband, C., Galloway, T.S., 2011. Microplastics as contaminants in the marine environment: A review. Marine Pollution Bulletin 62 (12), 2588-2597. https://doi.org/10.1016/j.marpolbul.2011.09.025.

Crawford, C.B., Quinn, B., 2017. Microplastic Pollutants. Elsevier, Amsterdam.

De-la-Torre, G.E., 2019. Microplastics: an emerging threat to food security and human health. J. Food Sci. Technol. https://doi.org/10.1007/s13197-019-04138-1.

Derraik, J.G.B., 2002. The pollution of the marine environment by plastic debris: a review. Mar. Pollut. Bull. 44, 842-852. https://doi.org/10.1016/S0025-326X(02) 00220-5.

Eo, S., Hong, S.H., Song, Y.K., Lee, J., Lee, J., Shim, W.J., 2018. Abundance, composition, and distribution of microplastics larger than $20 \mu \mathrm{m}$ in sand beaches of South Korea. Environ. Pollut. 238, 894-902. https://doi.org/10.1016/j.envpol.2018.03.096.

Esiukova, E., 2017. Plastic pollution on the Baltic beaches of Kaliningrad region, Russia. Mar. Pollut. Bull. 114, 1072-1080. https://doi.org/10.1016/j.marpolbul.2016.10. 001.

Gray, A.D., Wertz, H., Leads, R.R., Weinstein, J.E., 2018. Microplastic in two South Carolina Estuaries: occurrence, distribution, and composition. Mar. Pollut. Bull. 128, 223-233. https://doi.org/10.1016/j.marpolbul.2018.01.030.

Guzzetti, E., Sureda, A., Tejada, S., Faggio, C., 2018. Microplastic in marine organism: environmental and toxicological effects. Environ. Toxicol. Pharmacol. 64, 164-171. https://doi.org/10.1016/j.etap.2018.10.009.

Hengstmann, E., Tamminga, M., vom Bruch, C., Fischer, E.K., 2018. Microplastic in beach 
sediments of the Isle of Rügen (Baltic Sea) - implementing a novel glass elutriation column. Mar. Pollut. Bull. 126, 263-274. https://doi.org/10.1016/j.marpolbul.2017. 11.010 .

Heo, N.W., Hong, S.H., Han, G.M., Hong, S., Lee, J., Song, Y.K., Jang, M., Shim, W.J., 2013. Distribution of small plastic debris in cross-section and high strandline on Heungnam beach, South Korea. Ocean Sci. 48, 225-233 doi:10.1007\%2Fs12601-0130019-9.

Hernandez-Gonzalez, A., Saavedra, C., Gago, J., Covelo, P., Santos, M.B., Pierce, G.J., 2018. Microplastics in the stomach contents of common dolphin (Delphinus delphis) stranded on the Galician coasts (NW Spain, 2005-2010). Mar. Pollut. Bull. 137, 526-532. https://doi.org/10.1016/j.marpolbul.2018.10.026.

Hidalgo-Ruz, V., Thiel, M., 2013. Distribution and abundance of small plastic debris on beaches in the SE Pacific (Chile): a study supported by a citizen science project. Mar Environ Res 87-88, 12-18. https://doi.org/10.1016/j.marenvres.2013.02.015.

Hinojosa, I.A., Thiel, M., 2009. Floating marine debris in fjords, gulfs and channels of southern Chile. Mar. Pollut. Bull. 58, 341-350. https://doi.org/10.1016/j.marpolbul. 2008.10.020.

Hitchcock, J.N., Mitrovic, S.M., 2019. Microplastic pollution in estuaries across a gradient of human impact. Environ. Pollut. 247, 457-466. https://doi.org/10.1016/j.envpol. 2019.01.069.

Isobe, A., Kubo, K., Tamura, Y., Kako, S., Nakashima, E., Fujii, N., 2014. Selective transport of microplastics and mesoplastics by drifting in coastal waters. Mar. Pollut. Bull. 89, 324-330. https://doi.org/10.1016/j.marpolbul.2014.09.041.

Jayasiri, H.B., Purushothaman, C.S., Vennila, A., 2013. Quantitative analysis of plastic debris on recreational beaches in Mumbai, India. Mar. Pollut. Bull. 77, 107-112. https://doi.org/10.1016/j.marpolbul.2013.10.024.

Karthik, R., Robin, R.S., Purvaja, E., Ganguly, D., Anandavelu, I., Raghuraman, R., Hariharan, G., Ramakrishna, A., Ramesh, R., 2018. Microplastics along the beaches of southeast coast of India. Sci. Total Environ. 645, 1388-1399. https://doi.org/10. 1016/j.scitotenv.2018.07.242

Koongolla, J.B., Andrady, A.L., Kumara, P.B.T.P., Gangabadage, C.S., 2018. Evidence of microplastics pollution in coastal beaches and waters in southern Sri Lanka. Mar. Pollut. Bull. 137, 277-284. https://doi.org/10.1016/j.marpolbul.2018.10.031.

Kwon, B.G., Koizumi, K., Chung, S.Y., Kodera, Y., Kim, J.O., Saido, K., 2015. Global styrene oligomers monitoring as new chemical contamination from polystyrene plastic marine pollution. J. Hazard. Mater. 300, 359-367. https://doi.org/10.1016/j. jhazmat.2015.07.039.

Kwon, B.G., Amamiya, K., Sato, H., Ching, S.Y., Kodera, Y., Kim, S.K., Lee, E.J., Saido, K., 2017. Monitoring of styrene oligomers as indicators of polystyrene plastic pollution in the North-West Pacific Ocean. Chemosphere 180, 500-505. https://doi.org/10. 1016/j.chemosphere.2017.04.060.

Laglbauer, B.J.L., Franco-Santos, R.M., Andreu-Cazenave, M., Brunelli, L., Papadatou, M., Palatinus, A., Grego, M., Deprez, T., 2014. Macrodebris and microplastics from beaches in Slovenia. Mar Pollut Bull 89, 356-366. https://doi.org/10.1016/j.envpol. 2018.02.050.

Lee, J., Lee, J.S., Jang, Y.C., Hong, S.Y., Shim, W.J., Song, Y.K., Hong, S.H., Jang, M., Han, G.M., Kang, D., Hong, S., 2015. Distribution and size relationships of plastic marine debris on beaches in South Korea. Arch. Environ. Contam. Toxicol. 69, 288-298. https://doi.org/10.1007/s00244-015-0208-x.

Lots, F.A.E., Behrens, P., Vijver, M.G., Horton, A.A., Bosker, T., 2017. A large-scale investigation of microplastic contamination: abundance and characteristics of microplastics in European beach sediment. Mar. Pollut. Bull. 123, 2019-2226. https://doi. org/10.1016/j.marpolbul.2017.08.057.

Matsuguma, Y., Takada, H., Kumata, H., Kanke, H., Sakurai, S., Suzuki, T., Itoh, M., Okazaki, Y., Boonyatumanond, R., Zakaria, M.P., Weerts, S., Newman, B., 2017. Microplastics in sediment cores from Asia and Africa as indicators of temporal trends in plastic pollution. Arch. Environ. Contam. Toxicol. 73, 230-239. https://doi.org/ 10.1007/s00244-017-0414-9.

McDermid, K.J., McMullen, T.L., 2004. Quantitative analysis of small-plastic debris on beaches in the Hawaiian archipelago. Mar. Pollut. Bull. 48, 790-794. https://doi.org/ 10.1016/j.marpolbul.2003.10.017

Mu, J., Qu, L., Jin, F., Zhang, S., Fang, C., Ma, X., Zhang, W., Huo, C., Cong, Y., Wang, J., 2019. Abundance and distribution of microplastics in the surface sediments from the northern Bering and Chukchi Seas. Environ. Pollut. 245, 122-130. https://doi.org/ 10.1016/j.envpol.2018.10.097.

Naidu, S.A., 2019. Preliminary study and first evidence of presence of microplastics and colorants in green mussel, Perna viridis (Linnaeus, 1758), from southeast coast of India. Mar. Pollut. Bull. 140, 416-422. https://doi.org/10.1016/j.marpolbul.2019. 01.024 .

Ory, N.C., Sobral, P., Ferreira, J.L., Thiel, M., 2017. Amberstripe scad Decapterus muroadsi (Carangidae) fish ingest blue microplastics resembling their copepod prey along the coast of Rapa Nui (Easter Island) in the South Pacific subtropical gyre. Sci. Total Environ. 586, 430-437. https://doi.org/10.1016/j.scitotenv.2017.01.175.

Ory, N., Chagnon, C., Felix, F., Fernández, C., Ferreira, J.L., Gallardo, C., Ordóñez, O.G., Henostroza, A., Laaz, E., Mizraji, R., Mojica, H., Haro, V.M., Medina, L.O., Preciado, M., Sobral, P., Urbina, M.A., Thiel, M., 2018. Low prevalence of microplastic contamination in planktivorous fish species from the southeast Pacific Ocean. Mar. Pollut. Bull. 127, 211-216. https://doi.org/10.1016/j.marpolbul.2017.12.016.

PlasticsEurope, 2018. Plastics - the facts 2017: an analysis of European plastics production, demand and waste data. https://www.plasticseurope.org/application/files/ 5715/1717/4180/Plastics_the_facts_2017_FINAL_for_website_one_page.pdf, Accessed date: 19 February 2019.

Provencher, J.F., Vermaire, J.C., Avery-Gomm, S., Braune, B.M., Mallory, M.L., 2018 Garbage in guano? Microplastic debris found in faecal precursors of seabirds known to ingest plastics. Sci. Total Environ. 644, 1477-1484. https://doi.org/10.1016/j. scitotenv.2018.07.101.

Purca, S., Henostroza, A., 2017. Microplastic presence in four sandy beaches of Peru. Rev. Peru. Biol. 24, 101-106 (in Spanish).

Qiu, Q., Peng, J., Yu, X., Chen, F., Wang, J., Dong, F., 2015. Occurrence of microplastics in the coastal marine environment: first observation on sediment of China. Mar. Pollut. Bull. 98, 274-280. https://doi.org/10.1016/j.marpolbul.2015.07.028.

Rebolledo, E.L.B., Van Franeker, J.A., Jansen, O.E., Brasseur, S.M.J.M., 2013. Plastic ingestion by harbour seals (Phoca vitulina) in the Netherlands. Mar. Pollut. Bull. 67, 200-202. https://doi.org/10.1016/j.marpolbul.2012.11.035.

Shim, W.J., Hong, S.H., Eo, S., 2018. Marine microplastics: abundance, distribution, and composition. In: Zeng, E.Y. (Ed.), Microplastic Contamination in Aquatic Environments - An Emerging Matter of Environmental Urgency, 1st edn. Elsevier, Amsterdam, pp. 1-26.

Thiel, M., Luna-Jorquera, G., Álvarez-Varas, R., Gallardo, C., Hinojosa, I.A., Luna, N., Miranda-Urbina, D., Morales, N., Ory, N., Pacheco, A.S., Portflitt-Toro, M., Zavalaga, C., 2018. Impacts of marine plastic pollution from continental coasts to subtropical gyres - fish, seabirds, and other vertebrates in the SE Pacific. Front. Mar. Sci. 5, 238. https://doi.org/10.3389/fmars.2018.00238.

Tiwari, M., Rathod, T.D., Ajmal, P.Y., Bhagare, R.C., Sahu, S.K., 2019. Distribution and characterization of microplastics in beach sand from three different Indian coastal environments. Mar. Pollut. Bull. 140, 262-273. https://doi.org/10.1016/j. marpolbul.2019.01.055.

Wessel, C.C., Lockridge, G.R., Battiste, D., Cebrian, J., 2016. Abundance and characteristics of microplastics in beach sediments: insights into microplastic accumulation in northern Gulf of Mexico estuaries. Mar. Pollut. Bull. 109, 178-183. https://doi.org/ 10.1016/j.marpolbul.2016.06.002.

Wu, C., Zhang, K., Xiong, X., 2017. Microplastic pollution in inland waters focusing on Asia. In: Wagner, M., Lambert, S. (Eds.), Freshwater Microplastics. The Handbook of Environmental Chemistry, 1st edn. vol 58. Springer, Cham, pp. 85-99.

Yu, X., Peng, J., Wang, J., Wang, K., Bao, S., 2016. Occurrence of microplastics in the beach sand of the Chinese inner sea: the Bohai Sea. Environ. Pollut. 214, 722-730. https://doi.org/10.1016/j.envpol.2016.04.080.

Zhu, J., Yu, X., Zhang, Q., Li, Y., Tan, S., Li, D., Yang, Z., 2019. Cetaceans and microplastics: first report of microplastic ingestion by a coastal delphinid, Sousa chinensis. Sci. Total Environ. 659, 649-654. https://doi.org/10.1016/j.scitotenv.2018.12.389. 